\title{
Corticotropin Releasing Hormone Stimulation Test and Nocturnal Cortisol Levels in Normal Children
}

\author{
RONALD E. DAHL, SELMA F. SIEGEL, DOUGLAS E. WILLIAMSON, PETER A. LEE, \\ JAMES PEREL, BORIS BIRMAHER, AND NEAL D. RYAN \\ Departments of Psychiatry and Pediatrics, University of Pittsburgh School of Medicine and \\ Western Psychiatric Institute and Clinic, Pittsburgh, Pennsylvania 15213
}

\begin{abstract}
This study examined hypothalamic-pituitary-adrenal axis functioning in a group $(n=25)$ of very carefully screened normal children with considerable attention to issues of adaptation and procedural stress. The subjects (mean age 10.3 $\pm 1.6 \mathrm{y}$ ) were selected as "supernormal" controls as a part of a large psychobiologic study of childhood depression. After careful acclimatization over $24 \mathrm{~h}$, the subjects underwent all-night sampling of plasma cortisol every $20 \mathrm{~min}$, then the following evening had a corticotropin releasing hormone (CRH) stimulation test (using human CRH). Human CRH resulted in a rapid stimulation of adrenocorticotropin and cortisol. Adrenocorticotropin levels increased from $6.8 \pm 3.5( \pm \mathrm{SD}) \mathrm{pmol} / \mathrm{L}$ $(30.7 \pm 16.1 \mathrm{pg} / \mathrm{dL})$ to a peak of $11.6 \pm 5.5 \mathrm{pmol} / \mathrm{L}(52.9$ $\pm 24.8 \mathrm{pg} / \mathrm{mL}$ ) at $15 \mathrm{~min}$ with return to baseline levels by $60 \mathrm{~min}$. Cortisol levels increased from $131.4 \pm 59.7 \mathrm{nmol} /$ $\mathrm{L}(4.8 \pm 2.2 \mu \mathrm{g} / \mathrm{dL})$ to a peak of $427.0 \pm 113.5 \mathrm{nmol} / \mathrm{L}$ $(15.5 \pm 4.1 \mu \mathrm{g} / \mathrm{dL})$ at $30 \mathrm{~min}$ with return to baseline by $120 \mathrm{~min}$. The cortisol peak was significantly greater $(p<$ $0.05)$ in boys $[474.6 \pm 129.7 \mathrm{nmol} / \mathrm{L}(17.2 \pm 4.7 \mu \mathrm{g} / \mathrm{dL})]$ than in girls $[366.9 \pm 52.4 \mathrm{nmol} / \mathrm{L}(13.3 \pm 1.9 \mu \mathrm{g} / \mathrm{dL}, p<$ 0.05)]. Age, body mass index, and pubertal status were not significantly related to hypothalmic-pituitary-adrenal axis measures. Nocturnal cortisol reached a nadir at $160 \pm 60$ min after sleep onset $(0102 \mathrm{~h})$ and a peak $480 \pm 60 \mathrm{~min}$ after sleep onset $(0612 \mathrm{~h})$. Nocturnal cortisol levels were significantly (positively) correlated with human CRH-stimulated cortisol $(r=0.56, p=0.004)$. There was also significant correlation between sleep continuity and nocturnal cortisol (Spearman rho $=-0.55, p=0.005$ ) and between sleep continuity and human CRH-stimulated cortisol (Spearman rho $=-0.53, p=0.008$ ). These significant correlations across different stress measures indicate the importance of individual (subject) differences in patterns of stress response. These results also highlight the need to consider procedural, subjective, and psychologic factors when conducting tests measuring stress hormone levels in children. (Pediatr Res 32: 64-68, 1992)
\end{abstract}

\section{Abbreviations}

HPA, hypothalamic-pituitary-adrenal CRH, corticotropin-releasing hormone hCRH, human corticotropin-releasing hormone ACTH, adrenocorticotropin

Received November 14, 1991; accepted February 24, 1992.

Correspondence: Ronald E. Dahl, M.D., Western Psychiatric Institute and Clinic, 3811 O'Hara Street, Room E733, Pittsburgh, PA 15213.

Supported by NIMH Grant MH-41712 to Joaquim Puig-Antich, M.D.
BMI, body mass index

$\mathrm{CV}$, coefficient of variation

F, cortisol

The measurement of "normal" levels of stress hormones in children presents a problem analogous to the conundrum described by Heisenburg (1927, "Uncertainty Principle") in physics: there are inherent limitations to measuring the system without directly influencing what is being quantified. That is, the process of assessing HPA axis functioning in children often creates at least moderate stress related to the procedures. Typically, these stressors include venipunctures for serum hormone levels, administration of unfamiliar substances (such as CRH or dexamethasone), a somewhat threatening environment (such as a hospital or clinic), interactions with potentially threatening strangers (doctors and nurses), and possibly separation from parents. There is clear evidence that even moderate psychologic stressors, such as public speaking (1), hospitalization (2), and school examinations (3), can stimulate the HPA axis. Individual characteristics of the child, (including age, cognitive abilities, psychologic factors, and previous experiences), can significantly influence the subjective experience of these procedural stressors by the child. For example, a young, anxious child with specific fears of medical procedures can demonstrate extreme physiologic responses merely anticipating a medical encounter, whereas another child with good cognitive understanding and support may undergo a complex procedure with relatively little physiologic stress.

In the context of clinically assessing children with possible endocrine disorders, this realm of psychologic and procedural stresses influencing HPA axis measures has received little attention. It is generally assumed that these factors account for minimal variance in serum cortisol measures compared to clinically significant endocrine dysfunction. To delineate normal HPA axis physiology and development, however, some consideration must be given to these psychologic and procedural influences (and to the individual characteristics of the child that may influence the subjective experience of the procedural stresses).

This realm of procedural and psychologic factors is also central to understanding endocrine dysfunction associated with psychiatric disorders. There is substantial literature documenting altered HPA axis functioning in adult depressed subjects that is hypothesized to be related to an altered vulnerability to stress (4). Similar studies in child and adolescent depression, however, have yielded inconsistent results, with a number of large, wellcontrolled studies failing to find significant HPA abnormalities associated with depression in this young age group (5-8). Important sources of variance in these studies include procedural 
stresses, adaptation, psychologic factors, and individual characteristics influencing cortisol measures in normal control children, as well as in the depressed subjects.

The present study was designed to control and minimize identifiable factors in this realm (as much as possible) in normal control children. Specifically the goals were to 1 ) eliminate children with psychologic or psychiatric disorders; 2) eliminate children with medical disorders or a history of significant medical problems; 3) carefully orient the child and family to all procedures; 4) provide a comfortable, low-stress environment, with age-appropriate activities and unlimited family visitation; and 5) carefully acclimatize these normal children to the environment, procedures, and staff before obtaining measures. Although a primary purpose of this study was to provide normative (control) data for similar measures in depressed children, it also created a unique opportunity to examine normal HPA axis physiology in carefully screened, normal children adapted to the testing environment. The effects of age, sex, socioeconomic status, and pubertal status and the interrelationship of physiologic measures of stress are examined.

The specific HPA assessments in this study include baseline, (overnight) serum cortisol sampling, and CRH stimulation test. The CRH stimulation test has become a valuable diagnostic tool to investigate HPA function. CRH (a 41-amino acid peptide localized in the paraventricular nuclei of the hypothalamus) stimulates the release of ACTH and $\beta$-endorphin from the pituitary (9). Exaggerated ACTH responses to CRH stimulation help differentiate Cushing's disease from other causes of hypercortisolism, including primary affective disorders $(4,10-12)$. Previous reports have described responses in normal children (13) to ovine CRH administered in the evening, and responses in obese children or "normal" short children to human CRH administered in the morning (14-16). This report provides well-controlled normative data on ACTH and cortisol response to human CRH administered in the evening as well as baseline nocturnal cortisol levels.

\section{MATERIALS AND METHODS}

Subjects. This study was approved by the Institutional Review Board of the University of Pittsburgh. Informed consent was obtained from parents and assent from the child. Children in this study were normal controls for a large psychobiologic study of early onset depression. The children and their families were carefully screened for medical and psychiatric disorders. By design, they were selected to form a group of "supernormals" for the purpose of the psychiatric studies. Families were recruited through printed advertisements, health fairs, direct mailings, and personal contacts. All subjects had a medical history, physical examination, laboratory tests (including electrolytes, liver function, thyroid function, renal function, urinalysis, complete blood count, and ECG), and a comprehensive psychiatric evaluation. In addition, first and second degree relatives of the research subjects were assessed for psychiatric disorders by the family study method using DSM-III-R criteria (17). Over $90 \%$ of all first degree relatives were directly interviewed for these assessments. Families were paid for their participation. All children were between 6 and 13 y of age. Exclusion criteria were 1) presence or history of psychiatric illness or significant medical disorder; 2) taking any medications (except acetaminophen) within 2 wk of the study; 3 ) obesity (greater than $150 \%$ of ideal body weight); 4) height or weight below the 3rd percentile; and 5) intelligence quotient below 70 or a specific learning disability. A more complete description of the interviews, assessment process, and inclusionary criteria has been published previously (18).

Protocol. All studies were performed in a comfortable setting with a private bedroom and free access to a large recreational area. Unlimited family visitation was available throughout the protocol. Studies were usually performed over a weekend or during the summer. On the first day, an i.v. catheter was inserted into an antecubital vein and kept patent by slow infusion (with a mobile system that allowed free range of activities throughout the unit). EEG electrodes were placed before bedtime for sleep recordings. The first 24-h period of the protocol was for adaptation. On the second night, baseline nocturnal cortisol sampling (every $20 \mathrm{~min}$ ) began at bedtime and continued until morning awakening. Samples were drawn through a three-way stopcock system outside the subject's bedroom, permitting serum sampling without disturbing the subject's sleep. Subjects spent the remainder of the day at leisure in the unit, participating in activities such as movies and games with the staff. hCRH $(1.0 \mu \mathrm{g} / \mathrm{kg})$ i.v. infusion over $2 \mathrm{~min}$ was given at $1730 \mathrm{~h}$. Subjects had received nothing by mouth from $1400 \mathrm{~h}$ through the completion of the $\mathrm{hCRH}$ test. A physician and research nurse were in attendance throughout the test. Basal blood samples for ACTH and cortisol were obtained at $-30,-15$, and 0 min. After hCRH infusion, blood samples were obtained at 15, 30, 60, 90, 120, and 150 min. Blood samples, collected in EDTA (powder) tubes, were immediately centrifuged in a refrigerated centrifuge. Plasma was carefully separated and stored at $-80^{\circ} \mathrm{C}$ until assayed.

Cortisol. The Diagnostic Products Corp. (Los Angeles, CA) solid phase ${ }^{125}$ I RIA cortisol procedure was used with a sensitivity to $27.56 \mathrm{nmol} / \mathrm{L}(1 \mu \mathrm{g} / \mathrm{dL})$. Duplicate samples were assayed from $25-\mu \mathrm{L}$ samples with labeled antigen added into tubes coated with a highly specific cortisol antibody. The tubes were then incubated for $45 \mathrm{~min}$ at $37^{\circ} \mathrm{C}$, decanted, washed, and counted on a gamma spectrometer. Counts were inversely proportional to the amount of cortisol present in the standard curve and were converted into concentrations using logit/log representations. Patient duplicates exceeding a $5.0 \%$ coefficient of variation were retested. All samples from an individual patient were determined in the same assay. Mean intraassay CV was $1.8 \%$ with range of 1.3 to $2.7 \%$.

$A C T H$. Blood samples were drawn into chilled EDTA vacutainer tubes, mixed with aprotinin for protease inhibition, and centrifuged. Plasma was immediately frozen with N-ethylmaleimide. Modification of the double antibody, ${ }^{125}$ I RIA developed by Radioassay Systems Laboratory, Inc. (Carson, CA) was used. Sequential incubation of antibody and radiolabeled antigen was used to increase the sensitivity of the assay to $1.1 \mathrm{pmol} / \mathrm{L}(5 \mathrm{pg} /$ $\mathrm{mL}$ ). Triplicate samples, $100 \mu \mathrm{L}$, were incubated for $7 \mathrm{~h}$ at $4^{\circ} \mathrm{C}$ with the primary ACTH antibody. Radiolabeled antigen was added; incubation was continued for an additional $16 \pm 2 \mathrm{~h}$. Separation of bound and free analyte was accomplished using gamma globulin. After centrifugation, the supernatant was decanted and the pellet was counted on a gamma spectrometer. $\mathrm{ACTH}$ concentrations were determined using logit/log representations.

The limit of detectability was $1.1 \mathrm{pmol} / \mathrm{L}(5 \mathrm{pg} / \mathrm{mL})$; the range of the CV was $1.5-9.0 \%$ with an upper limit of $11.0 \mathrm{pmol} / \mathrm{L}$ (50 $\mathrm{pg} / \mathrm{mL}$ ) for linearity. The ACTH samples were diluted and measured with reliability at $1.1-11.0 \mathrm{pmol} / \mathrm{L}(5-50 \mathrm{pg} / \mathrm{mL})$. The interday variation for the assay ranged from $9.3 \% \mathrm{CV}$ [mean $11.8 \mathrm{pmol} / \mathrm{L}(53.5 \mathrm{pg} / \mathrm{mL})$ ] to $19.9 \% \mathrm{CV}$ [mean $1.9 \mathrm{pmol} / \mathrm{L}(8.6$ $\mathrm{pg} / \mathrm{mL})]$. This assay detects both the 1-39 and 1-24 molecular forms of human ACTH.

Statistical analysis. All variables were examined to determine if they were normally distributed using the W statistic (19). If the distribution was not normal, a logarithmic transformation was performed and the transformed value was reexamined to determine normality. All significance tests were performed with $\alpha=$ 0.05 . Statistical tests used were $t$ test, using pooled or separate estimates of variance as appropriate, and analysis of variance for repeated measures. Correlations were analyzed using Pearson (parametric) or Spearman (nonparametric) techniques as appropriate.

Definitions. The mean pre-hCRH response was defined as the mean of the -30-, -15-, and 0-min samples for both ACTH (pre-ACTH) and cortisol (pre-F). The peak post-hCRH was defined as the highest values after the administration of hCRH for both ACTH (peak post-ACTH) and cortisol (peak post-F). 
The $\Delta$ was defined as the pre-hCRH mean value subtracted from the peak value $(\Delta-\mathrm{ACTH}$ and $\Delta-\mathrm{F})$. The mean post-hCRH response is the mean of the 15-, 30-, 60-, and 90-min samples (mean post-ACTH and mean post-F). Descriptive variables for nocturnal cortisol include the mean over the night, the peak (highest value of the night), the nadir (lowest value), the time of the peak, and the time of the nadir. All hormone measures in the text are given as means $\pm \mathrm{SD}$.

Sample. The sample consisted of 25 children with a mean age of $10.3 \pm 1.6 \mathrm{y}$ (range 7.1 to $13.4 \mathrm{y}$ ). The mean \pm SD for height SD score for the group was $0.09 \pm 1.42$. BMI was $18.0 \pm 3.0$. There were 14 boys and 11 girls. Tanner staging (based on breast/ testes and pubic hair development) revealed an even split between Tanner I and II (with one male subject Tanner III and one male subject Tanner IV). As a result of the selection process for supernormals (for psychiatric control purposes), this group was composed of children with relatively high socioeconomic status and a high rate of intact (two parent) households. The mean Hollingshead score was $47.0 \pm 13.0$.

Only a subset (17 of 25 subjects) had ACTH measures after hCRH stimulation tests, so only this subset was considered in sections dealing with ACTH and ACTH/cortisol relationships.

\section{RESULTS}

hCRH-stimulated ACTH (Table 1, Fig. 1). The pre-ACTH levels increased from $6.8 \pm 3.5 \mathrm{pmol} / \mathrm{L}(30.7 \pm 16.1 \mathrm{pg} / \mathrm{mL})$ to a mean peak of $11.6 \pm 5.5 \mathrm{pmol} / \mathrm{L}(52.9 \pm 24.8 \mathrm{pg} / \mathrm{mL})$, giving a mean $\Delta$-ACTH of $4.9 \pm 3.0 \mathrm{pmol} / \mathrm{L}(22.2 \pm 13.8 \mathrm{pg} / \mathrm{mL})$. In 13 of 17 patients with ACTH measures, the peak ACTH level occurred at $15 \mathrm{~min}$. In three of 17 , the ACTH peak occurred at 30 min. In a single patient, no ACTH response could be detected with a basal value of $25.8 \mathrm{pg} / \mathrm{mL}$ and maximum value of 25.8 $\mathrm{pg} / \mathrm{mL}$ at $60 \mathrm{~min}$. By analysis of variance for repeated measures for the group, both the 15- and 30-min ACTH levels were greater

Table 1. Cortisol and ACTH response to CRH in normals*

\begin{tabular}{lrr}
\hline & Mean \pm SD & \multicolumn{1}{c}{ Range } \\
\hline Cortisol response & & \\
Mean pre-CRH-F & $131.4 \pm 59.7$ & $34.9-281.2$ \\
Peak post-CRH-F & $427.0 \pm 113.5$ & $291.4-742.4$ \\
$\Delta$-F (peak post minus mean & $295.6 \pm 119.0$ & $55.7-580.4$ \\
$\quad$ pre-CRH) & & \\
ACTH response & & \\
Mean pre-CRH-ACTH & $6.8 \pm 3.5$ & $3.3-15.5$ \\
Peak post-CRH-ACTH & $11.6 \pm 5.5$ & $5.7-26.4$ \\
$\Delta$-ACTH (peak post minus & $4.9 \pm 3.0$ & $0.0-11.0$ \\
mean pre-CRH) & & \\
\hline
\end{tabular}

*Values are mean $\pm \mathrm{SD}$ in $\mathrm{nmol} / \mathrm{L}$ for cortisol $(\mathrm{F}), \mathrm{pmol} / \mathrm{L}$ for $\mathrm{ACTH}$, with range indicating lowest and highest values.

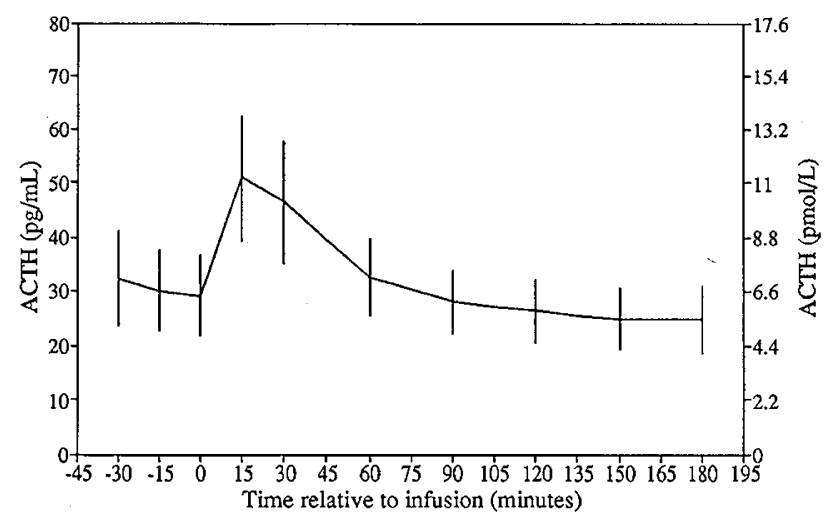

Fig. 1. ACTH response to CRH. Normal children $(n=17)$. Values are mean \pm SEM. than the basal level $(p<0.0001)$. Levels at 60 and 90 min posthCRH infusion were no longer significantly higher than baseline. hCRH-stimulated cortisol (Table 1, Fig. 2). Mean pre-F levels increased from $131.4 \pm 59.7 \mathrm{nmol} / \mathrm{L}(4.8 \pm 2.2 \mu \mathrm{g} / \mathrm{dL})$ to a mean peak $F$ of $427.0 \pm 113.5 \mathrm{nmol} / \mathrm{L}(15.5 \pm 4.1 \mu \mathrm{g} / \mathrm{dL})$, giving a mean $\Delta-\mathrm{F}$ of $295.6 \pm 119.0 \mathrm{nmol} / \mathrm{L}(10.7 \pm 4.3 \mu \mathrm{g} / \mathrm{dL})$. In 24 of 25 subjects, the peak $F$ level occurred at $30 \mathrm{~min}$. The peak occurred at $60 \mathrm{~min}$ in a single patient. [The patient with no detectable ACTH response had a peak cortisol response at 30 min with incremental elevation of $204.2 \mathrm{nmol} / \mathrm{L}(7.4 \mu \mathrm{g} / \mathrm{dL})]$. For the group, by analysis of variance for repeated measures, cortisol was significantly above baseline at 15, 30, 60, and 90 min, but not different from baseline by 120 and $150 \mathrm{~min}$.

We examined the effects of sex, age, BMI, pubertal status, and socioeconomic status on summary variables of cortisol and ACTH. The cortisol peak was greater in boys [472.6 \pm 129.6 $\mathrm{pmol} / \mathrm{L}(17.2 \pm 4.7 \mathrm{pg} / \mathrm{mL})]$ than in girls $[366.9 \pm 52.4 \mathrm{pmol} / \mathrm{L}$ $(13.3 \pm 1.9 \mathrm{pg} / \mathrm{mL}, p<0.05)]$ (Fig. 3). There were no significant effects of age or BMI on cortisol or ACTH measures. There were no significant differences between Tanner I and Tanner II subjects (because only two subjects were beyond Tanner stage II, effects of more advanced pubertal status could not be analyzed). Socioeconomic status was significantly (negatively) correlated with peak post-ACTH levels (Spearman rho $=-0.58, p<0.01$ ).

Cortisol/ACTH relationship. The $\Delta-\mathrm{ACTH}$ and $\Delta-\mathrm{F}$ were positively correlated $(r=0.56, p=0.02)$. However, there was no significant correlation between peak $\mathrm{F}$ and peak ACTH values after hCRH $(r=0.29, p=0.25)$. We also examined the relationship between pre-F levels and CRH response. These analyses revealed nonsignificant trends: the correlation between pre-F and $\Delta-\mathrm{F}$ was $-0.32(p=0.11)$ and between pre-F and $\Delta-\mathrm{ACTH}$ was $-0.36(p=0.15)$.

Nocturnal cortisol (Fig. 4). Nocturnal cortisol levels reached a

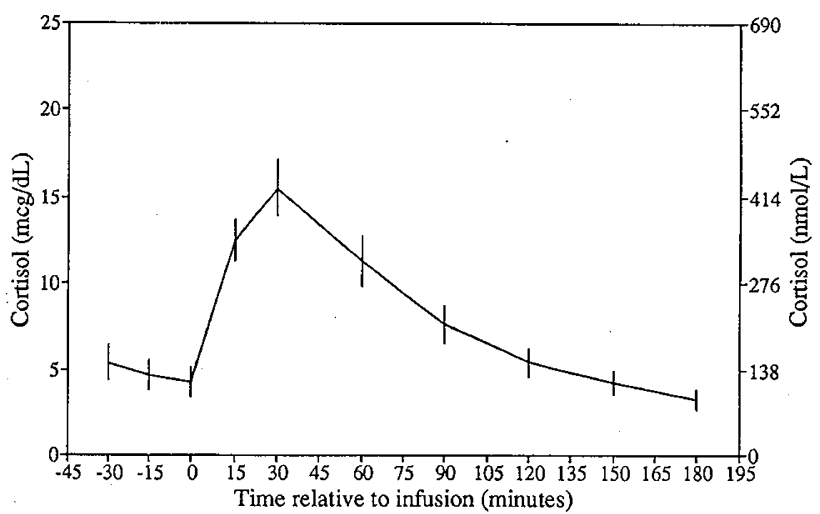

Fig. 2. Cortisol response to CRH. Normal children $(n=25)$. Values are mean \pm SEM.

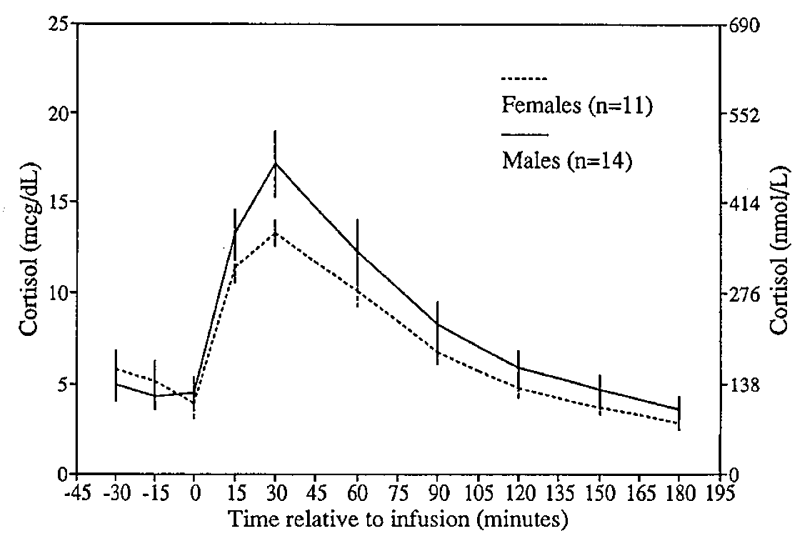

Fig. 3. Cortisol response to CRH. Males vs. females. Values are mean $\pm \mathrm{SEM}$. 
nadir at $160 \pm 60 \mathrm{~min}$ after sleep onset of $19.3 \pm 16.5 \mathrm{nmol} / \mathrm{L}$ $(0.7 \pm 0.6 \mu \mathrm{g} / \mathrm{dL})$ and reached a peak at $480 \pm 60 \mathrm{~min}$ after sleep onset of $482.8 \pm 121.4 \mathrm{nmol} / \mathrm{L}(17.5 \pm 4.4 \mu \mathrm{g} / \mathrm{dL})$. These correspond to times of $0102 \mathrm{~h}$ for the nadir and $0612 \mathrm{~h}$ for the peak. The mean value across the night was $165.5 \pm 57.9 \mathrm{nmol} /$ $\mathrm{L}(6.0 \pm 2.1 \mu \mathrm{g} / \mathrm{dL})$.

The mean nocturnal cortisol level showed a significant (positive) correlation with the mean post-hCRH-F $(r=0.56$, $p=0.004)$, and peak nocturnal cortisol correlated with peak hCRH-F $(r=0.54, p=0.006)$.

$E E G$ sleep measures/cortisol. The positive correlations between two different cortisol measures (nocturnal cortisol and $\mathrm{hCRH}-\mathrm{F}$ ) prompted us to examine another physiologic measure of stress outside the HPA axis: EEG sleep measures. We had obtained EEG sleep measures in this study to compare sleep in depressed children with sleep in normal controls (20). To further examine stress responses, we focused on one sleep variable (sleep maintenance) most closely linked with stress and adaptation. [Sleep maintenance is the percentage of minutes in the total sleep period spent asleep; it reflects the frequency and duration of sleep disturbances and has been shown to decrease in children undergoing stress or adaptation (21).] We hypothesized that subjects with the highest nocturnal cortisol level and largest hCRH-F measure would show the lowest sleep maintenance, reflecting a generalized pattern of increased stress responses. Post hoc analyses supported this hypothesis, revealing a significant negative correlation between sleep maintenance and nocturnal cortisol (Spearman rho $=-0.55, p=0.005$ ) and between sleep maintenance and post-hCRH-F (Spearman rho $=-0.53, p=$ 0.008 ).

\section{DISCUSSION}

These data provide a unique description of normative HPA axis function in a carefully selected group of normal children. Because these 25 children were serving as controls in a large psychiatric study, they were carefully screened both medically and psychiatrically, and the subjects and their families had a good understanding of the procedures. They were well acclimatized to the comfortable environment and adapted to the procedures, including the indwelling venous catheter, before hormone levels were measured.

CRH resulted in a rapid response of $\mathrm{ACTH}$, with 13 of the 17 patients showing peak ACTH responses at $15 \mathrm{~min}$. The peak cortisol response occurred at $30 \mathrm{~min}$ in all but one subject. These results are consistent with our understanding of the physiology of CRH-ACTH-cortisol secretion. ACTH responses were back to baseline by $60 \mathrm{~min}$, and cortisol levels were back to baseline by $120 \mathrm{~min}$.

Two studies in children using $\mathrm{CRH}$ reported peak $\mathrm{ACTH}$ responses at $30 \mathrm{~min}$; however, they did not measure levels at 15

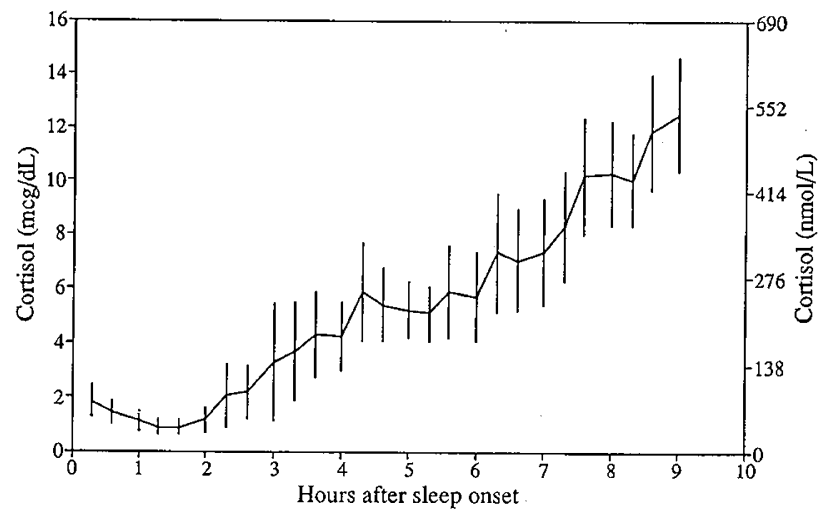

Fig. 4. Nocturnal cortisol secretion. Normal children $(n=25)$. Values are mean \pm SEM. $\min (14,15)$. Although the majority of children in our study had peak ACTH levels by $15 \mathrm{~min}$, we speculate that peak ACTH response may occur even earlier based on past studies of cortisol response at $10 \mathrm{~min}(22)$. These results are also consistent with the findings of Attanasio et al. (16), who reported peak ACTH at $10 \mathrm{~min}$ and peak cortisol at $15-30 \mathrm{~min}$.

Among the most intriguing findings from this study were the significant correlations among the three different stress measures (nocturnal cortisol, CRH-F, and sleep maintenance). These findings indicate that individual (subject) differences may account for significant variance in the pattern of stress responses across measures. This is consistent with the work of Kagan et al. (23), who have shown that a subgroup of children with behavioral inhibition ("cautious and shy children") have elevated physiologic responses to novelty, whereas another subgroup, behaviorally uninhibited ("fearless and outgoing children"), show small physiologic stress responses. This concept is also supported by the findings of Mathews et al. (24), who found stability in the rank order of cardiovascular responses to behavioral stresses in a 4-y longitudinal study of normal children after controlling for age, sex, BMI, and task performance.

These individual differences could by physiologically based (e.g. certain individuals may biologically demonstrate more robust responses to generalized stressors). An additional possibility is that these individual differences are influenced by psychologic factors. For example, certain subjects may be more anxious or slower to adapt to the procedures and staff during the protocol. It is important to emphasize that these individual differences appear to be significant in this study despite the design, which attempted to minimize these factors by carefully screening out subjects with psychologic disorders and by carefully acclimatizing the subjects to the environment, procedures, and staff. That is, with respect to these psychologic and procedural factors, we believe that this was a relatively homogenous group (high socioeconomic status, intact families, subjects and families free of psychiatric illness) and a design that minimized procedural stress.

The significant differences related to sex and socioeconomic status are intriguing, but should be interpreted with caution, inasmuch as these findings were not predicted and results were not protected (statistically) for the number of comparisons. (Also, the pattern of findings was not significant in both ACTH and cortisol values.) We are not aware of other data showing elevated cortisol in males; however, one previous study reported significantly higher corticosteroid binding globulin in girls compared to age-matched boys (13).

The strengths of this study (careful selection of supernormals and careful adaptation in a comfortable environment) also create some important limitations. Specifically, these results may not be strictly comparable to results obtained in a hospital or clinic setting where the same control and acclimatization are not possible. Thus, although these data reflect normal physiology, they may not provide "normal" values applicable for clinical tests conducted in a hospital setting where it is not feasible to comparably control stress surrounding the procedures. On the other hand, the same cautions would apply to interchanging normal values from previous studies because there is no reason to believe that the amount of stress associated with clinical procedures is in any way "standard" or controlled across clinical centers.

These results would also appear to have important implications relevant to clinical endocrine assessments. Despite the homogeneity of subjects and procedures, these results demonstrated different patterns of stress responses among subjects. Some children showed a robust response across measures (increased cortisol at night, increased cortisol after hCRH, and more disturbed sleep), whereas others showed low responses across measures. These results (consistent patterns of stress responses in individuals) highlight the need to consider the procedural, subjective, and psychologic factors that may impact on clinical tests involving stress hormones. These factors, interactions between proce- 
dural stressors and psychologic factors, could potentially interfere with the ability to accurately detect endocrine disorders. For example, the combination of a stressful procedure in clinic and a tendency toward robust stress response (and/or a particularly anxious child) could result in a failure to suppress cortisol after dexamethasone in a normal child (false-positive dexamethasone suppression test). Conversely, inadequate adrenal reserve may be masked by an initial normal acute rise of cortisol to ACTH stimulation in response to a stressful procedure in an anxious subject (the possibility of a false-negative test for Addison's). Further evaluation of the magnitude of these procedural and psychologic factors in the context of clinical endocrine disorders in children could clarify diagnostic procedures of the HPA axis.

It also appears evident that a better understanding of the normal physiology of stress responses in children will require more interdisciplinary research, not only to clarify procedural issues, but also to delineate the interaction between biologic variation and psychologic factors.

Acknowledgments. This paper is dedicated to the memory of Dr. Puig-Antich, who died in December of 1989. The authors thank the staff of the Child and Adolescent Sleep/Neuroendocrine Laboratory at Western Psychiatric Institute and Clinic under the direction of Beverly Nelson, R.N., for the patient and skillful management of the children in this study and Deborah Small for her assistance with the manuscript preparation.

\section{REFERENCES}

1. Baumgartner A, Graf KJ, Kurten I 1985 Serial dexamethasone suppression tests in psychiatric illness: I. A study in schizophrenia and mania. Psychiatry Res 18:9-23

2. Cocarro E, Prudic J, Roghpeerl A, Nurnberg H 1984 Effect of hospitalization on DST results. Am J Psychiatry 141:982-985

3. Tennes K, Kreye M 1985 Children's adrenocortical response to classroom activities and tests in elementary school. Psychosom Med 47:451-460

4. Gold PW, Loriaux DL, Roy A, Kling MA, Calabrse JR, Kellner CH, Nieman LK, Post RM, Pickar D, Gallucci W, Avgerinos P, Paul S, Oldfield EH, Cutler Jr GB, Chrousos GP 1986 Responses to corticotropin-releasing hormone in the hypercortisolism of depression and Cushing's disease. $\mathrm{N}$ Engl $\mathbf{J}$ Med 314:1329-1335

5. Puig-Antich J, Dahl RE, Ryan N, Novacenko H, Goetz D, Twomey J, Klepper $T 1989$ Cortisol secretion in prepubertal children with major depressive disorder. Arch Gen Psychiatry 46:801

6. Dahl RE, Puig-Antich J, Ryan ND, Nelson B, Novacenko H, Twomey J, Williamson D, Goetz R, Ambrosini PJ 1989 Cortisol secretion in adolescents with major depressive disorder. Acta Psychiatr Scand 80:18-26

7. Dahl RE, Ryan ND, Puig-Antich J, Nguyen NA, Al-Shabbout M, Meyer VA,
Perel J 1991 24-hour cortisol measures in adolescents with major depression: a controlled study. Biol Psychiatry 30:25-36

8. Birmaher B, Ryan ND, Dahl RE, Rabinovich $\mathrm{H}$, Ambrosini $\mathrm{P}$, Williamson DE, Novacenko H, Nelson B, Sing Lo, E, Puig-Antich J 1992 Dexamethasone suppression test in children with major depressive disorder. J Am Acad Child Adolesc Psychiatry 31:291-297

9. Vale W, Rivier C, Brown MR, Spiess J, Koob G, Swanson L, Bilizikjian L, Bloom F, Rivier J 1983 Chemical and biological characterization of corticotropin releasing factor. Recent Prog Horm Res 39:245-270

10. Chrousos GP, Schulte HM, Oldfield EH, Gold PW, Cutler Jr GB, Loriaux DL 1984 The corticotropin releasing factor stimulation test: an aid in the evaluation of patients with Cushing's disease. N Engl J Med 310:622

11. Chrousos GP, Schurmeyer TH, Doppman J, Oldfield EH, Schulte HM, Gold PW, Loriaux DL 1985 Clinical applications of corticotropin-releasing factor. Ann Intern Med 102:344-358

12. Gomez Muguruza MT, Chrousos GP 1989 Periodic Cushing's syndrome in a short boy: usefulness of the ovine corticotropin releasing hormone test. J Pediatr 115:270-273

13. Ross JL, Schulte HM, Gallucci WT, Cutler Jr GB, Loriaux DL, Chrousos GP 1986 Ovine corticotropin-releasing hormone stimulation test in normal children. J Clin Endocrinol Metab 62:390-392

14. Goji K 1989 The corticotropin-releasing hormone test in normal short children: comparison of plasma adrenocorticotropin and cortisol responses to human corticotropin-releasing hormone and insulin-induced hypoglycemia. Acta Endocrinol (Copenh) 120:390-394

15. Bernasconi S, Petraglia F, Iughetti L, Marceilini C, Lamborghini A, Facchinetti F, Ganazzani AR 1988 Impaired beta-endorphon response to human corticotropin-releasing hormone in obese children. Acta Endocrinol (Copenh) 119:7-10

16. Attanasio A, Robkamp R, Bernasconi S, Terzi C, Ranke MB, Giovanelli D, Gupta D 1987 Plasma adrenocorticotropin, cortisol, and dehydroepiandrosterone response to corticotropin-releasing factor in normal children during pubertal development. Pediatr Res 22:1:41-44

17. American Psychiatric Association 1987 Diagnostic and Statistical Manual of Mental Disorders: DSM-III-R, 3rd Ed. American Psychiatric Association, Washington, DC

18. Ryan ND, Birmaher B, Perel JM, Dahl RE, Meyer V, Al-Shabbout M, Iyengar S, Puig-Antich J 1992 Neuroendocrine response to L-5-hydroxytryptophan challenge in prepubertal major depression: depressed versus normal children. Arch Gen Psychiatry (in press)

19. Shapiro SS, Wilkes MB 1965 An analysis of variance test for normality (complete sample). Biometrika 52:591-611

20. Dahl RE, Ryan ND, Birmaher B, Al-Shabbout M, Williamson DE, Neidig M, Nelson B, Puig-Antich J 1991 EEG sleep measures in prepubertal depression. Psychiatry Res 38:201-214

21. Coble PA, Kupfer DJ, Reynold CF, Houck P 1987 EEG sleep of healthy children 6 to 12 years of age. In: Guilleminault C (ed) Sleep and Its Disorders in Children. Raven Press, New York, pp 29-41

22. Siegel SF, Finegold DN, Lee PA 1990 A ten minute ACTH stimulation test? Programs and abstracts of the 72nd Annual Meeting of the Endocrine Society, Atlanta, GA

23. Kagan J, Reznick JS, Snidman N 1987 The physiology and psychology of behavioral inhibition in children. Child Dev 58:1459-1473

24. Mathews K, Woodall KL, Stoney C 1990 Changes in and stability of cardiovascular responses to behavioral stress: results from a four-year longitudinal study of children. Child Dev 61:1134-1144 